\title{
Regional Marketing Implementation Structure within the Formation of the Region's Ecosystem
}

\author{
Mariya V. Shendo 1[ORCID 0000-0002-2924-6050], \\ Elena V. Sviridova 1[ORCID 0000-0002-9232-5405], \\ Ekaterina V. Kravec $\left.{ }^{2 *[O R C I D} 0000-0003-3036-0907\right]$, \\ Olga P. Ivanova 3[ORCID 0000-0002-9563-4166]
}

\author{
${ }^{1}$ Astrakhan State Technical University, Astrakhan, Russia \\ ${ }^{2}$ LEONOV Moscow Region University of Technology, Korolev, Russia \\ ${ }^{3}$ Yaroslav-the-Wise Novgorod State University, Veliky Novgorod, Russia \\ kravec_e_v@mail.ru
}

\begin{abstract}
The concept of ecosystems is becoming more and more popular and has its uses not only in business, but also in public management, both in the country and in individual regions. This is actively facilitated by the development of digital technologies and their introduction into production and private life. The article is devoted to the development of a model of the ecosystem of a region. The tasks of the study have been to systematize theoretical approaches to regional management, to define the essence of the ecosystem approach, to analyze the possibility of its application in domestic practice of regional management based on studying the experience of its application in domestic business, to analyze the economic prerequisites for the concept of the ecosystem of a region on the example of the Southern Federal District of the Russian Federation (SFD), to develop a model of the ecosystem of a region. The main research methods have been structural-logical, system-logical, bibliographic, and statistical analyses. The theoretical foundation of the approaches to region management has been analyzed; the authors' concept of the ecosystem approach within the framework of public management has been formed. The expediency of using the concept of an ecosystem within the framework of regional management has been substantiated on the basis of an analysis of several economic indicators of the development of the SFD and its constituent entities. As a result of bibliographic analysis, four main research discourses of the ecosystem concept have been identified including a business ecosystem, a platform-based ecosystem, and a regional ecosystem. A model of the ecosystem of a region has been formed based on region marketing, the use of its tools, taking into account active digitalization of the country's economy, and the introduction of the ecosystem approach into the practice of domestic business. The given model of the ecosystem of a region has been proposed for analytical studies on public management, the design of marketing strategies and management tactics for socio-economic entities, a region, a macroregion, and a country.
\end{abstract}

Keywords: ecosystem approach, region's ecosystem, region marketing

\section{INTRODUCTION}

The process of globalization accelerated by digital technologies has led to the fact that the whole world is regarded as a single market. However, the resources for the development of this market remained limited, which constrains the economic growth of individual regions and forces them to enter into a competition among themselves for investment, labor, and qualified personnel capable of creating economic benefits.

One of the ways to outpace the competitors is to combine the efforts of various elements of the regional system, while creating conditions for the formation of new consumer values, for increasing the competitiveness and attractiveness of the region.

Moving beyond value creation within individual 
companies, firms have integrated customers, partners, and other interested parties into the process of co-creating mutual value [1].

This method is successfully used by commercial companies, creating ecosystems under their names that can meet the most diverse needs of the client. Gradually, companies with partly state capital start to do the same. Regions can learn from the accumulated experience and adapt it to their characteristics of public management.

For this, it is initially necessary to study the theoretical basis of the issue under study, to analyze the experience of domestic business from a perspective of regional marketing and the integration of marketing and modern digital technologies into the enterprise ecosystem. In addition, the economic situation in the region should be assessed. In this work, the Southern Federal District of the Russian Federation (hereinafter - SFD) acts as an object of research.

Based on the collected data, the authors propose to use a model of the ecosystem of a region within the framework of consumer-oriented marketing as a way of developing the region's economy.

\section{MATERIALS AND METHODS}

The purpose of the research is to develop a model of the ecosystem of a region.

Research objectives are the following:

- to systematize theoretical approaches to the management of a region;

- to define the essence of the ecosystem approach;

- to analyze the possibility of its application in the domestic practice of regional management based on the study of its application in domestic business;

- to analyze the economic prerequisites for the concept of the ecosystem of a region on the example of the SFD;

- to develop a schematic model of the ecosystem of a region.

The main research methods are structurallogical, system-logical, bibliographic, and statistical analyses.

The methodological basis of the study is the theoretical approaches to the management of regional development, the ecosystem concept, and the accumulated experience of domestic business.

\section{RESULTS}

Management of regional development is the main task of the authorities, within the framework of which an increase in the competitiveness of the region is achieved. The approach to management as a set of tools and measures on the way to the set strategic goal of regional development is also important. Figure 1 presents a set of theoretical approaches with their essence and brief description.

\section{THEORY AND}

CONCEPT

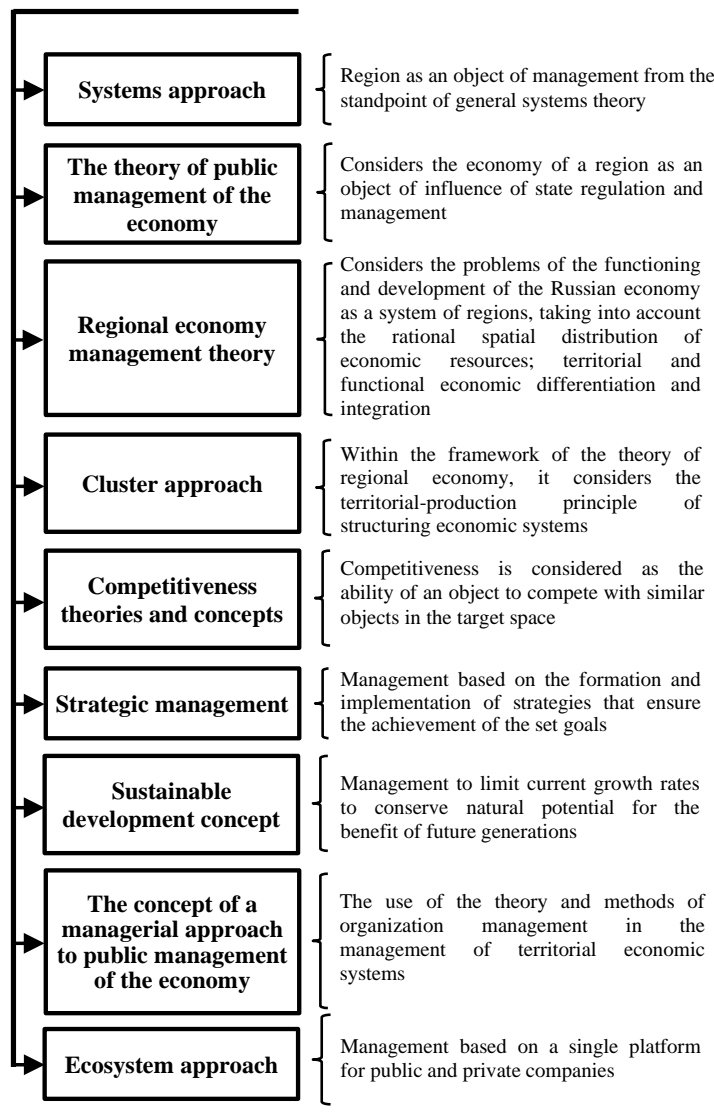

Figure 1. Approaches to managing regional development

Source: Compiled by the authors based on [2]

Ecosystem approach. The object of management is a region as an ecosystem that includes a set of key elements that coexist simultaneously in cooperation and competition. The approach is based on the integration of information on all key regional subsystems into a single system and the integration of public and private companies into a single ecosystem to create new consumer values. The management methodology is applicable within the 
framework of the digitalization of the economy, and the platform for working with the consumer is formed using digital technologies and is aimed, first of all, at ensuring the competitiveness of the region. The more open the system, the easier it is to attract suppliers to expand the product range, but the quality may suffer. The degree of openness should be determined in part by what matters most to the end customer. That is, if it is an ecosystem containing confidential data about clients or this ecosystem ensures the safety of clients, then the degree of its openness is inversely proportional to its reliability [3].

As digital technologies continue to evolve and gain popularity, they begin to create new ways of organizing value creation. This means moving from value chains to digital ecosystems. This, in turn, is giving way to new types of businesses like Apple and Alibaba, which rely on the power of their digital ecosystems to achieve market dominance [4].

Companies are moving from remote monitoring to optimization, control, and, ultimately, autonomous systems with advanced functionality based on artificial intelligence [5].

Ecosystems are actively developing on the domestic market, including Sberbank, MTS, Tinkoff, Yandex, Mail.ru. These companies, thanks to digital technologies, have gone far beyond their industry and have become able to meet the needs of customers in a variety of areas, which allowed them to expand their target audience and diversify their business. Sberbank is a representative of companies that have both private funds and state funds in their capital. This suggests that the regional ecosystem is also capable of being formed, based on the needs of target groups of consumers, even though they belong to the most different spheres of life and activities of a person, company, state. An analysis of the ecosystems of the largest representatives of Russian business allows identifying such areas of needs as, for example, health (Docdoc, Smartmed, Yandex.Health); home (DomClick, Yandex.Realty, Realty.mail.ru); children (SberKids, Tinkoff Junior, MTS Razvivayka), etc.

Healthy competition, marketing technologies for the promotion and management of processes of meeting customer needs create conditions in which the buyer has a choice of services, the ability to form effective demand and ensure the growth and development of each of the above spheres of life. Thus, it is proposed to consider marketing, first of all, from the standpoint of forming optimal conditions at the regional level for the functioning of the mechanisms of a single regional ecosystem, while using all the opportunities provided by the marketing approach to managing the economic attractiveness of the region. Consider some economic indicators of regional development on the example of the SFD and its constituent entities.

The gross regional product (GRP) is one of the most important indicators of the development of a region, according to the dynamics of changes in which one can judge the general economic situation of the study area (Figure 2).

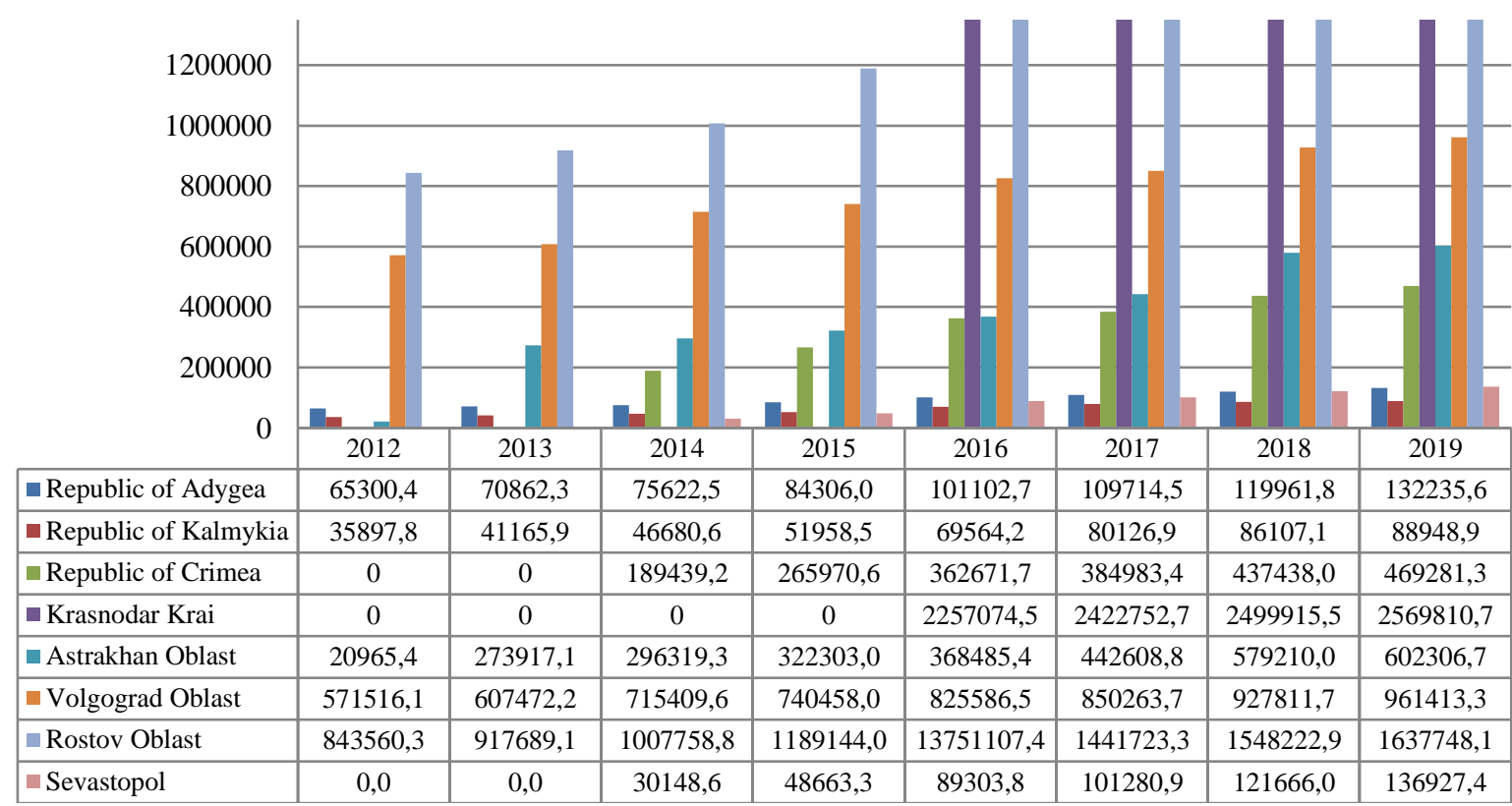

Figure 2. GRP by regions of the SFD for 2012-2019, million rubles at current prices Source: [6] 
The leaders in terms of GRP are Krasnodar Krai and the Rostov Oblast. The leadership indicators of the Volgograd Oblast are 30\% less and less than half of the leaders are the indicators of the Astrakhan Oblast. There is a steady growth in the GRP of the
Republic of Crimea. The leaders of the anti-rating are the Republic of Adygea, the Republic of Kalmykia, and the city of Sevastopol. The total GRP of the SFD (Figure 3) demonstrates progressive growth from year to year without failures.

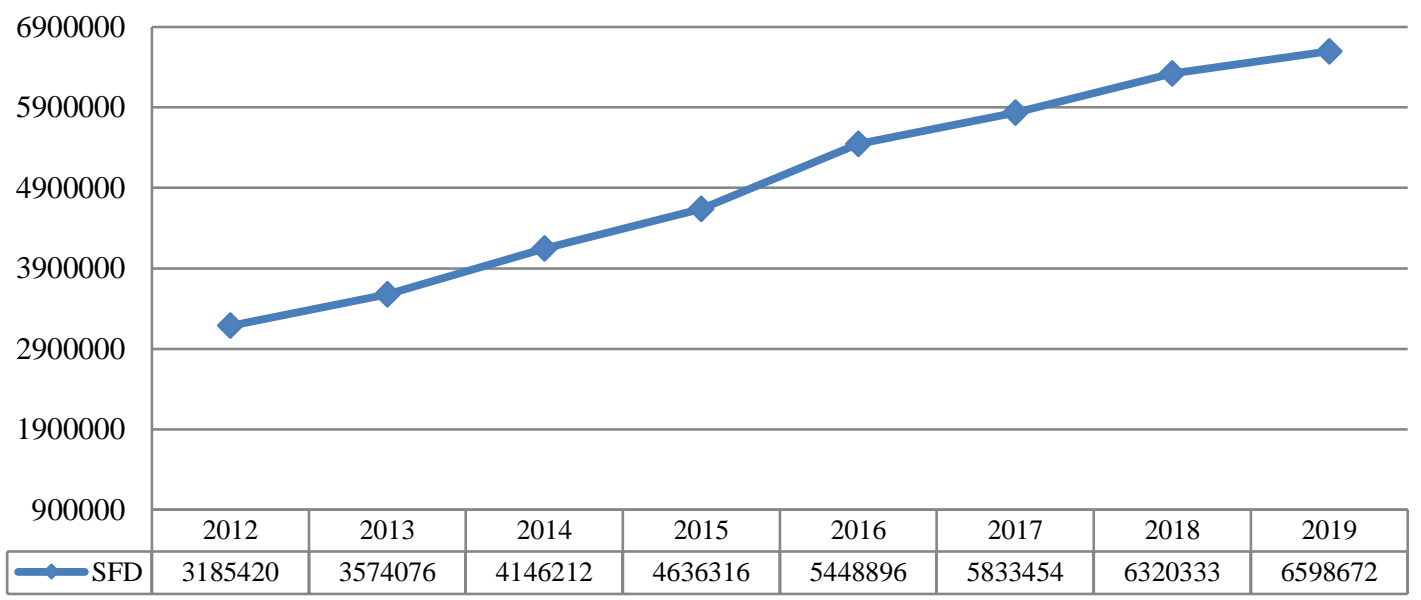

Figure 3. GRP in the SFD for 2012-2019, million rubles at current prices Source: [6]

This indicator for 2020 is questionable, as it became a crisis for all developed and developing economies of the world [5]. The investment attractiveness of a region is an indicator of its wellbeing and prospects for sustainable economic development. The investment activity of the southern regions of Russia is manifested in such an indicator as the share of investments in fixed assets to GRP (Figure 4), and this indicator is characterized by an investment deficit.

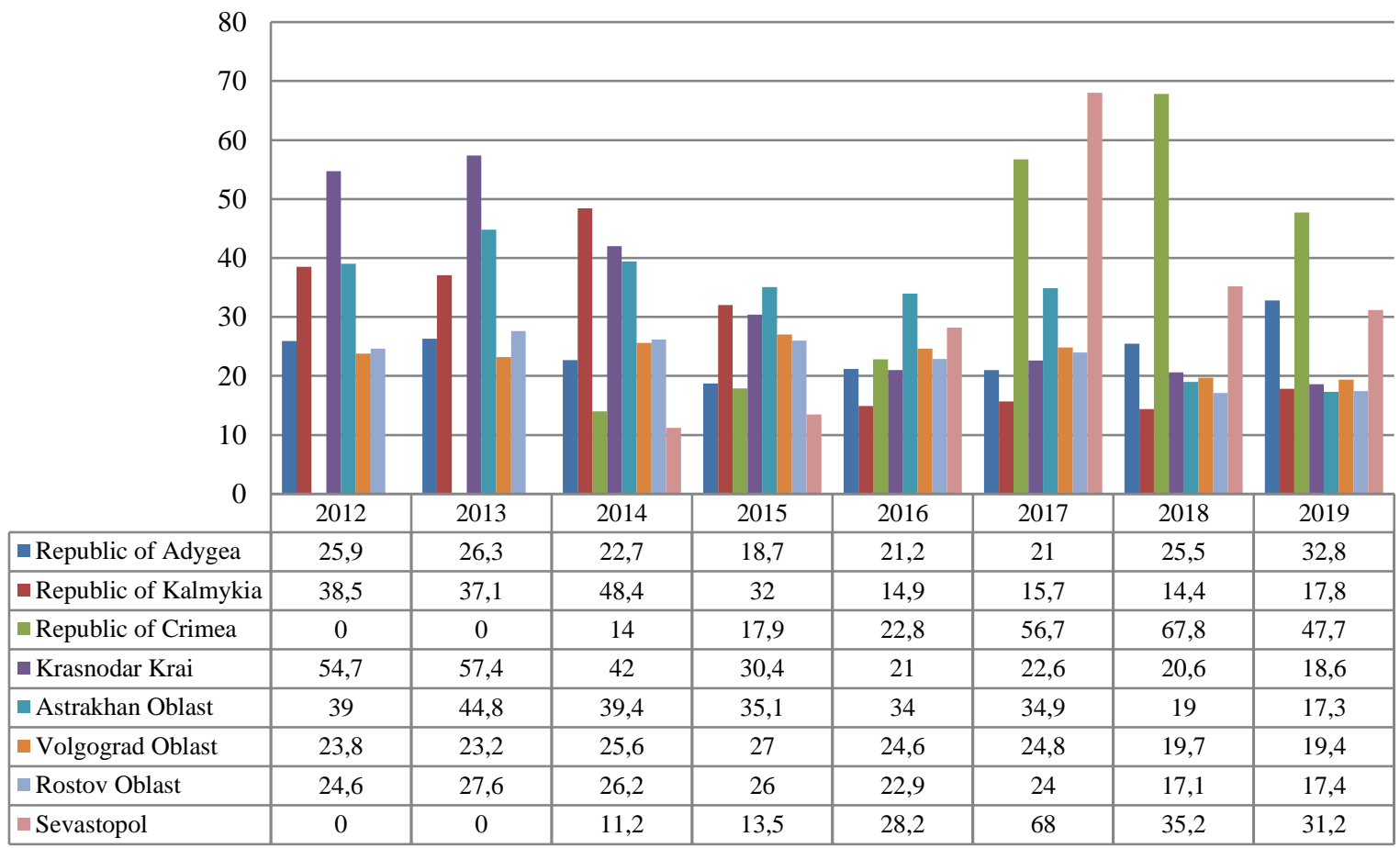

Figure 4. Share of investments in fixed assets to GRP by the regions of the SFD for 2012-2019, \% Source: [7]

By 2019, the share of investment in fixed assets $40 \%$ to $20 \%$, i.e. twice (Figure 5 ). 


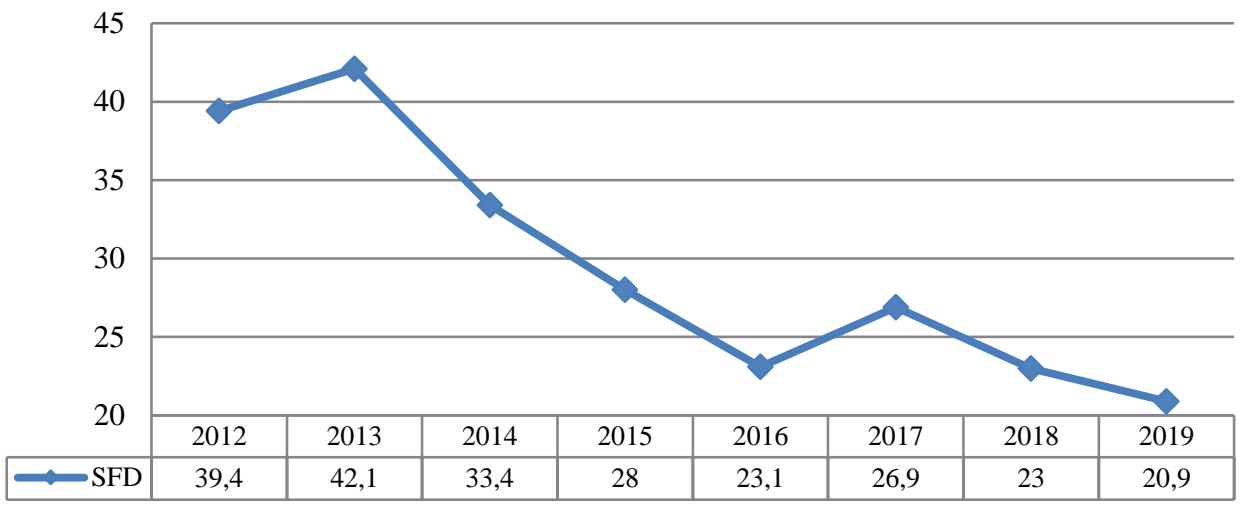

Figure 5. Share of investments in fixed assets to GRP in the SFD for 2012-2019, \% Source: [7]

However, investments are allocated both from the territory's own funds and are attracted from outside through participation in state programs for the development of individual sectors of the economy or by attracting private partners who see the prospects for the development of regional business (Figure 6).

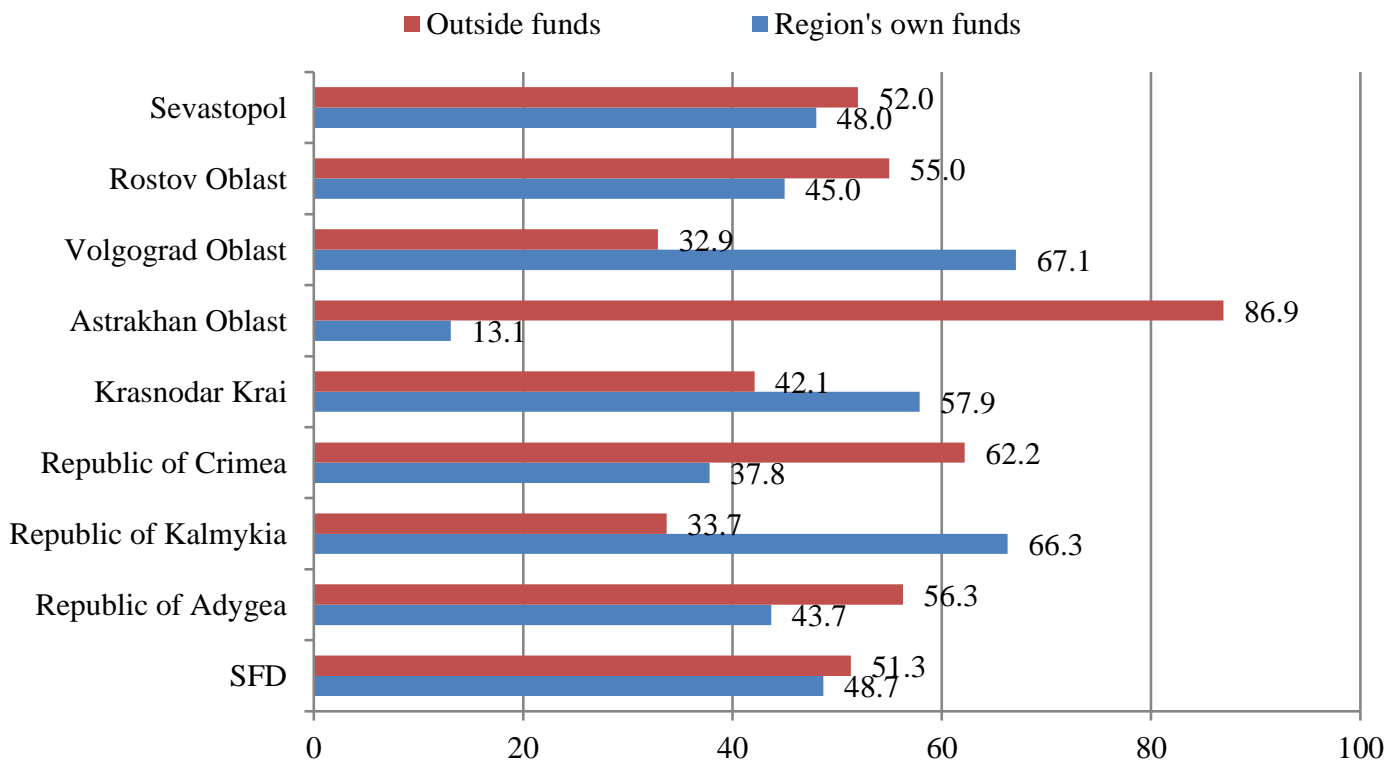

Figure 6. Structure of investments in fixed assets by sources of financing by the entities of the SFD in the first half of 2021, in \% of the total volume of investments in fixed assets

Source: [8]

The Astrakhan Oblast has very little of its own funds for investment, which indicates its direct dependence on external cash flows and an underdeveloped regional economy, which has been severely tested by the pandemic. The least vulnerable in this regard are the Volgograd Oblast and the Republic of Kalmykia which have more than $65 \%$ of their own capital investments in fixed assets [8].

Based on the above statistical information, the SFD can be characterized as follows:

- a territory of progressive economic growth with a deficit of investments, especially from own funds, which is facilitated by the poorly developed industrial component of the territories and the low potential of the economy;

- the number of industrial enterprises and employment in them is constantly decreasing, which forms the basis of the regional economy, while the district is more focused on trade, tourism, and the cultivation of certain agricultural branded crops than on the development of production;

- failure of the regions to reach the level of the 
country's average main indicators of economic development.

The process of capitalizing the economic resources of the SFD can be improved and stimulated on the condition of the creation of an ecosystem in the region, and, possibly, an enlarged ecosystem within the district or country with the use of marketing tools. Several spheres of the SFD economy are capable, with their correct integration, to capitalize these sectors and turn into a source of added value for a regional product.

The most effective way to develop regional markets is to use marketing tools as a means of increasing the attractiveness of the territory, improving its image, and creating the foundations of socio-economic growth with a consumer orientation. Thus, the SFD needs a marketing approach in the management of territories with the development of an operational, tactical, and strategic marketing policy which is to spell out the planned development of the territory in all the main areas of regional marketing.
The tasks of territorial marketing include determining the unique properties of the region that can attract investors, population, tourists, personnel and interest the state [9].

Digitalization contributes to the emergence of new services, the creation of platforms, smart products, and new business models [10].

In addition, commercial startups can serve as an example for the development of regional ecosystems, which, according to the research of specialists, have achieved a great effect by developing new platforms and integrating them into a common business ecosystem [11]. The management tools proposed in the study should be consolidated into a single structure for a deeper understanding of them and expanding the conditions for their use. To do this, it is necessary to develop a unified algorithm for the implementation of regional marketing based on the ecosystem approach, which is schematically shown in the figure below (Figure. 7).

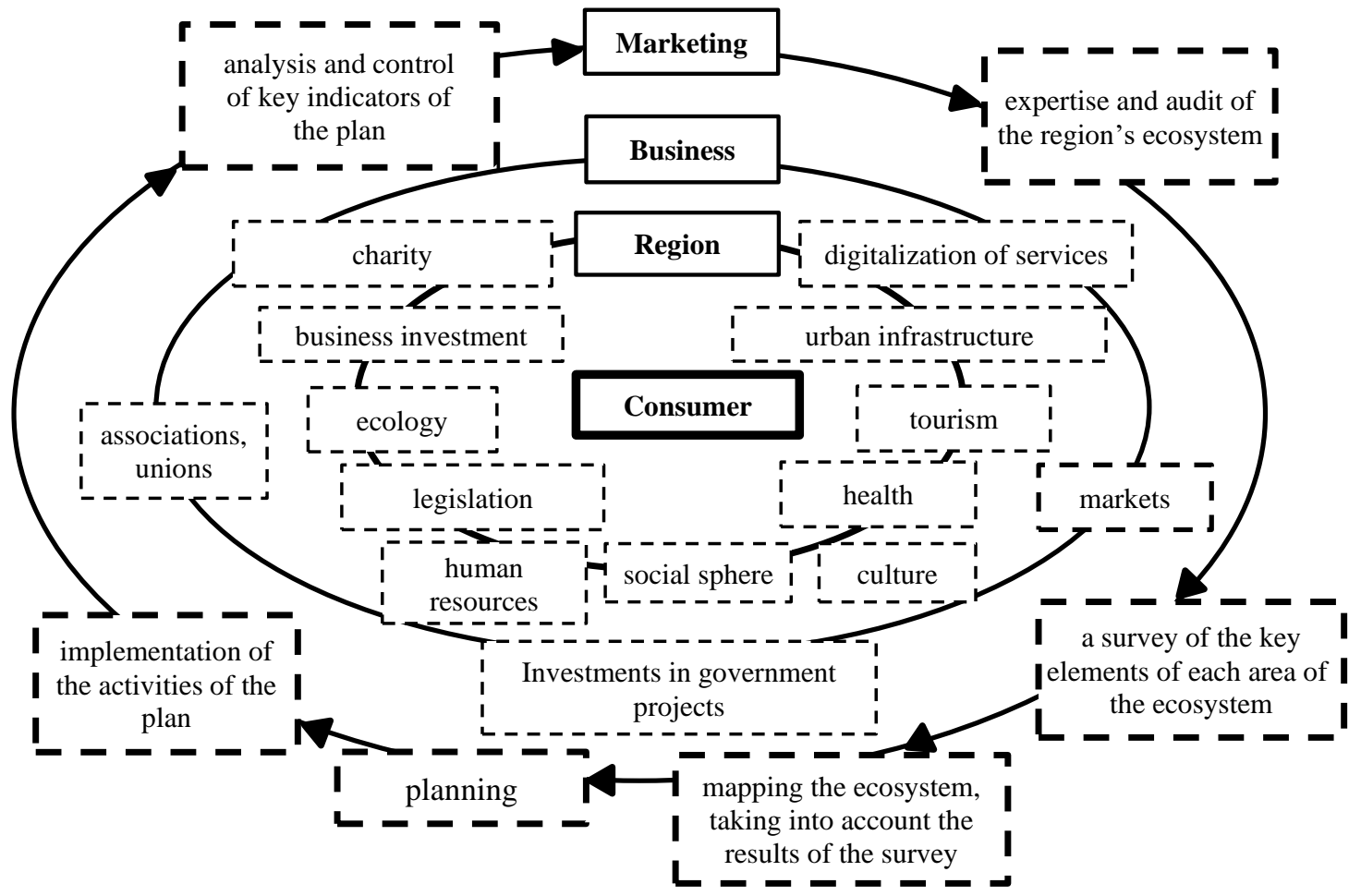

Figure 7. Structure of the region's ecosystem

Source: Compiled by the authors

The structure is presented schematically and may vary depending on the characteristics of each region. The authors propose to single out the following groups of consumers of a territorial product, as a key element and the first level of the ecosystem.
- individuals: residents and non-residents staying in the Astrakhan Oblast for a short period with specific purposes: tourism, business, business trip, participation in a competition, visiting relatives; 
- legal entities of various sectors of the economy that form the business climate of the region (enterprises, institutions, entrepreneurs, investors, insurers, representatives of public and professional associations and organizations);

- the state in the form of state institutions and as a recipient of tax revenues for the formation of the budget of the region and the country;

- external markets (regional, international).

The region as the second level of the ecosystem:

- urban infrastructure: residential areas (houses, gardens, schools, parks, medical institutions, roads), industrial zones (territories for zones in urban space and beyond, transport routes, transport hubs);

- market infrastructure (legislation, taxation conditions, credit and financial institutions, government agencies for registration and supervisory purposes, physical places for trade);

- tourism (attractions, hotels, guide and travel services);

- health (ecology, medical institutions, healthy lifestyle objects);

- culture (objects of leisure and entertainment, state policy in the sphere of culture);

- charity;

- $\quad$ social sphere;

- human resources;

- business investment;

- regional legislation;

- digital services (family and children, work, education, health, taxes and finance, transport and driving, registration, pension and benefits, production, culture, law and order, ecology, information, etc.).

Business as the third level of the ecosystem:

- charity;

- associations and unions;

- industry markets;

- digitalization of goods and services (health, home, education, children, work, media and entertainment, communications, finance, travel, cars, food and shopping, online shopping, mobility, etc.).

Marketing as the fourth level of the ecosystem, uniting all subsystems:

- image (creation of a brand of the territory, food brands of the region, the hospitality industry);

- attractiveness (improving the recognition of the region and its products, stimulating the desire of the population to live in the promoted territory);

- infrastructure (of cities, markets);

- population (personnel for the economy, support for schools and universities, the creation of business incubators, the introduction of innovations).

Stages of marketing a regional ecosystem:

1) expertise and audit of the regional ecosystem, search for the potential for development;

2) a survey of the key elements of each area of the ecosystem (population, scientists, politicians, representatives of small, medium, and large businesses);

3) mapping the ecosystem, taking into account the results of the survey;

4) planning (development of strategic and tactical plans for the development of the region);

5) implementation of the activities of the plan;

6) analysis and control of key indicators of the plan.

The success of ecosystem development in this context depends on the degree of focus of the region on target groups of consumers [12].

\section{DISCUSSION}

The economic indicators considered in the framework of the study are far from a complete list by which one can judge the economy of the region, which implies the use of a much wider range of statistical data indicators when auditing the socioeconomic state of a region.

It should also be noted that the success of the development of the scheme of the ecosystem of a region, proposed in the work, depends on the degree of its focus on target groups of consumers and the effectiveness of the use of marketing tools for creating an image, increasing attractiveness, 
developing infrastructure and marketing of the population in the process of implementing plans for the strategic and tactical development of the region.

\section{CONCLUSION}

One of the ways to compete is to combine the efforts of various elements of the regional system to create and effectively meet new consumer values, increase the competitiveness and attractiveness of a region. This method is successfully used by commercial companies, creating ecosystems of services under their name on various digital platforms, the range of which is able to meet the most diverse needs of the client. Gradually, companies with partly state capital start to do the same. The regions can learn from the accumulated experience and adapt it to their characteristics within the framework of public management. The better it turns out to integrate the work of individual elements of the territorial system into each other, the more chances are to create a full-fledged regional ecosystem that is resistant to fluctuations in the country's economy and the global market, in which the codependency of its elements should become a priority when forming a regional development strategy.

Management of regional development is the main task of the authorities, within the framework of which an increase in the competitiveness of the region is achieved. The approach to management as a set of tools and measures on the way to the set strategic goal of regional development is also important. The authors propose to supplement the existing approaches to managing regional development with an ecosystem approach, where the region as an object of management is represented as an ecosystem with a set of key elements that coexist simultaneously in cooperation and competition. The management methodology is applicable within the framework of the digitalization of the economy, and the platform for working with the consumer is formed using digital technologies and is aimed, first of all, at ensuring the competitiveness of the region.

Marketing, which puts the consumer at the center, is proposed to be considered from the standpoint of the formation of optimal conditions at the regional level for the functioning of the mechanisms of a single regional ecosystem while using all the opportunities provided by the marketing approach to managing the economic attractiveness of a region.

The economic attractiveness of a region is best reflected in the desire of various economic entities to invest in the region. In addition, GRP, as a fundamental indicator of regional development, has been studied by the authors in dynamics using the example of the SFD for eight years. Statistical analysis has shown that the total GRP of the SFD demonstrates progressive growth from year to year without failures, although the GRP of individual entities fluctuates. This indicator for 2020 which became a crisis for all developed and developing economies of the world is questionable. However, by 2019, the share of investments in fixed assets to GRP in the SFD collapsed, which means that investors do not see the prospects for the sustainable economic development of the region. The SFD really has several economic tasks to be solved which marketing will help to tackle as a way to attract resources from outside for the balanced production of economic and public goods and services, increasing the competitiveness of territorial goods and the continuous development of regional economic systems.

The authors present a schematic structure of the ecosystem of a region, which may vary depending on the characteristics of each region. Several elements of the system are considered in detail, but special attention is paid to the concept of a consumer and target segments since the consumer is at the center of the ecosystem. In this understanding, the consumer is a broad concept and is represented by individuals and legal entities, external markets in relation to the region and the state.

\section{AUTHORS' CONTRIBUTIONS}

The authors made an equal contribution to the study: collection and analysis of material; definition of goals and objectives, research methods; formulation and scientific substantiation of conclusions, registration of key research results in the form of an article.

\section{REFERENCES}

[1] A. Hein, J. Weking, M. Schreieck, M. Wiesche, "Value Co-Creation Practices in Business-toBusiness Platform Ecosystems", Electron Markets, 2019, vol. 29(3), pp. 503-518. DOI: 10.1007/s12525-019-00337-y

[2] D.V. Proskura, "Theory and methodology of regional competitiveness management" [Teoriya i metodologiya upravleniya konkurentosposobnost'yu regiona], Abstract of the dissertation for the degree of the Doctor of 
Economics, St. Petersburg, 2008. (In Russ.). Retrieved from http://disus.ru/rekonomika/139235-1-teoriya-metodologiyaupravleniya-konkurentosposobnostyuregiona.php

[3] M.G. Jacobides, "In the Ecosystem Economy, What's Your Strategy?", Harvard Business Review, 2019, vol. 97(5), pp. 128-137.

[4] O. Valdez-de-Leon, "How to Develop a Digital Ecosystem: A Practical Framework", Technology Innovation Management Review, 2019, vol. 7(8), pp. 43-54. DOI: $10.22215 /$ timreview/1260

[5] E. Carayannis, D.F.J. Campbell, "Triple Helix, Quadruple Helix and Quintuple Helix and How Do Knowledge, Innovation and the Environment Relate to Each Other?", International Journal of Social Ecology and Sustainable Development, 2010, vol. 1(1), pp. 41-69. DOI: $10.4018 /$ jsesd.2010010105

[6] "National accounts". Official website of the Rosstat, 2021. (In Russ.). Retrieved from https://rosstat.gov.ru/accounts

[7] "Efficiency of the Russian economy". Official website of the Rosstat, 2021. (In Russ.). Retrieved from
[8] "Investments in non-financial assets". Official website of the Rosstat, 2021. (In Russ.). Retrieved from https://rosstat.gov.ru/investment_nonfinancial

[9] K.A. Volkova, "Regional marketing as a tool for improving regional management system" [Regional'nyi marketing - instrument sovershenstvovaniia regional'noi sistemy upravleniia], Young Scientist [Molodoi uchenyi], 2018, vol. 5(191), pp. 152-154.

[10]M. Kohtamäki, V. Parida, P. Oghazi, H. Gebauer, "Digital servitization business models in ecosystems: a theory of the firm", Journal of Business Research, 2019, vol. 104, pp. 380-392. DOI: 10.1016/j.jbusres.2019.06.027

[11]Z.J. Acs, E. Stam, D.B. Audretsch, A. O'Connor, "The lineages of the entrepreneurial ecosystem approach", Small Business Economics, 2017, vol. 49(1), pp. 1-10. DOI: $10.1007 / \mathrm{s} 11187-017-9864-8$

[12] N.P. Ketova, "Regional marketing in system of tools and principles of management of territorial development", The Bulletin of the Adyghe State University: Internet Scientific Journal, 2012, vol. 1, pp. 153-163. (In Russ.).

https://rosstat.gov.ru/folder/11186 